\title{
AOR
}

Selected Papers of \#AolR2020:

The $21^{\text {st }}$ Annual Conference of the

Association of Internet Researchers

Virtual Event / 27-31 October 2020

\section{PRESENTING PERFECTION: CONSTRUCTING IDENTITY IN THE REHEARSAL STAGE OF ONLINE INTERACTION}

\author{
Dr Hannah Ditchfield \\ University of Sheffield
}

\begin{abstract}
Social media platforms have long been understood to present new opportunities for every day interaction and self presentation. Among these opportunities, however, there have been long-standing concerns surrounding the 'decline' or even 'death' of our social interaction and conversation (see The Guardian, 2012). Concerns around the quality of our digital conversations centre on how our online interaction is becoming shorter and more quantified, for example, through actions such as liking and sharing. Yet, social media users still engage in conversational dynamics that are more time consuming and less quantifiable, for example, writing posts and messages. Even in this context, though, scholars such as Sherry Turkle (2011) have argued that we 'flatten out what we say to each other' in new 'reductive' ways on digital platforms and that we are increasingly becoming accustomed to reductions within our daily interactions (p. 280). However, these debates have not been discussed from the 'pre-post' perspective of online interaction:that is, the activity and interactional work that occurs before ('pre') messages are sent ('posted') on social media platforms. This paper therefore provides a unique perspective on these issues by examining what the pre-post space online reveals about the quality of our digital interactions.
\end{abstract}

Interactional quality, in this paper, is understood through the Goffmanian notion of interactional order: the idea that interaction is entwined with rules and rituals that set expectations around the most appropriate or moral way to act and behave. Quality in this sense refers to a set of rules that encapsulates what it means to be 'appropriate' and 'moral' beings within our encounters with others. In this way, interactional order is intrinsically linked with the presentation of self (see Goffman, 1959): the more order is maintained, the more individuals perform appropriate and moral presentations of self. Due to this link, this paper addresses the concerns of the declining nature of our online interactions through the lens of identity construction. Like interaction, there have been long standing discussions regarding the opportunities and possibilities that social media 
platforms offer us in relation to identity construction (Marwick, 2013). These discussions, though, have also neglected the pre-post dimension: the space where users can change, edit, or completely restart an interaction before sharing with the intended audience.

Scholars have noted how the affordance of editability 'allows individuals to carefully craft the information being sent for a desired effect' (Quinn and Papacharissi, 2018, p. $359)$ giving users the opportunity to 'maintain a consistent presentation of self' and 'maximising their ability to generate a desired image' (p. 359). However, exactly how, and to what extent, social media users utilise the pre-post space to edit their messages is understudied and the link this has to ongoing debates of declining interaction remains unexplored. The pre-post space of online interaction has also, until now, not been theorised. This paper therefore presents this preparatory space as the 'rehearsal stage' of interaction. This argument extends Erving Goffman's (1967) conceptualisation of 'stages' and puts forward that pre-post editing occurs not in what he termed the 'front' or 'back' regions of interaction but instead in a 'rehearsal' space that is made possible through the architectural qualities of platforms like Facebook. The rehearsal stage is unique in the way it offers social media users a space to practice and draft their interactions before sharing such performances with their audience, offering a different form of interactional context to that of the front and back regions of interaction, both of which are accountable to others.

To reveal how Facebook users utilise the pre-post space real time recordings of Facebook interactions were collected. Through using screen capture technology participants recorded their screens whilst on the Facebook platform capturing the moment by moment edits made within their message constructions and revealing every change, edit and deletion made to messages before posting. Drawing on conversation analysis (Sacks, Schegloff and Jefferson, 1974), this research conducted a micro analysis of the screen capture data with a specific focus being given to how users accomplish certain presentations of self within their Facebook interactions. Through this analysis, the data revealed how the rehearsal stage of interaction plays a key role in processes of identity construction online. Previous work that has explored practices of pre-post editing (such as Meredith and Stokoe, 2014) revealed simple edits (such as word swaps that occur immediately within the typing out of a message or post). This analysis, however, unveiled an elaborate editing process in which users engage in several minutes of work that including multiple edits, large deletions and complete rewrites with users altering presentations of self drastically in this preparatory space of online interaction (see full paper: Ditchfield, 2020). 
Due to the level of complexity and the laborious nature of the pre-post editing captured in this research, this paper argues that the quality of online interaction is not in decline as previous arguments suggest (Turkle, 2011). Instead, I argue that the act perfecting one's presentation online is itself a form of reduction. Through the rehearsal stage and act of pre-post editing, the inconsistencies and messiness of offline face to face communication and identity are lost in the attempt to perfectly construct self. In this way, concerns of decline and quality should instead be directed towards the reduced and 'flattened out' self instead of our reduced interaction. With the ability to carefully craft our presentations of self, it is essential to consider what the implications of presenting 'perfect' selves and lives may be and calls into question what, if any, pressures this creates for users to put forward consistent perfection. With increasing attention to the discourse of digital detoxes and growing concerns around social media and mental health, this article argues that critical perspectives on these issues are increasingly pressing.

\section{References}

Ditchfield $\mathrm{H}$ (2020) Behind the screen of Facebook: identity construction in the rehearsal stage of online interaction, New Media \& Society, 22(6): 927-943

Goffman E (1959) The Presentation of Self in Everyday Life. New York: Anchor Books.

Goffman E (1967) Interaction Ritual. Chicago, IL: Aldine Publishing Company.

Marwick A (2013) Online identity. In: Hartley J, Burgess $\mathrm{J}$ and Bruns A (eds) A Companion to New Media Dynamics. Chichester: John Wiley \& Sons, pp. 355-364.

Meredith J and Stokoe E (2014) Repair: comparing facebook 'chat' with spoken interaction. Discourse \& Communication 8(2): 181-207.

Quinn K and Papacharissi Z (2018) Our networked selves: personal connection and relational maintenance in social media use. In: Burgess $\mathrm{J}$, Marwick $A$ and Poell $\mathrm{T}$ (eds) The SAGE Handbook of Social Media. London: SAGE, pp. 353-371.

Sacks H, Schegloff E and Jefferson G (1974) A simplest systematics for the organisation of turn- taking for conversation. Language 50(4): 696-735.

The Guardian (2012) Now everyone is connected, is this the death of conversation? Available at: https://www.theguardian.com/commentisfree/2012/apr/26/everyoneconnected-death-of- conversation (accessed 13 April 2019).

Turkle S (2011) Alone Together: Why We Expect More from Technology and Less from Each Other. New York: Basic Books. 